DOI: https://doi.org/10.24127/ajpm.v10i2.3489

\title{
PROSES BERPIKIR VISUAL MATEMATIS SISWA EXTROVERT DAN INTROVERT SEKOLAH MENENGAH ATAS BERDASARKAN TAHAPAN BOLTON
}

\author{
Erika Christin Trisnawarni $^{1}$, Tri Nova Hasti Yunianta ${ }^{2 *}$ \\ 1,2* Pendidikan Matematika, Universitas Kristen Satya Wacana, Indonesia \\ *Corresponding author \\ E-mail: $\quad \frac{\text { 202017017@student.uksw.edu }}{\text { trinova.yunianta@uksw.edu }^{2 * 1}}$
}

Received 19 January 2021; Received in revised form 19 June 2021; Accepted 29 June 2021

\begin{abstract}
Abstrak
Kemampuan berpikir visual penting untuk dimiliki siswa sehingga diperlukan penelitian lebih lanjut untuk melihat proses berpikir visual siswa. Penelitian ini dilakukan untuk mendeskripsikan proses berpikir visual berdasarkan tahapan Bolton pada siswa Sekolah Menengah Atas dengan tipe kepribadian extrovert atau introvert saat menyelesaikan masalah matematis. Subjek dalam penelitian ini 2 siswa kelas XII yang berkepribadian extrovert dan 2 siswa introvert. Teknik pengambilan data dalam penelitian yaitu dokumentasi, non-tes/tes, dan wawancara. Analisis data yang digunakan adalah reduksi, penyajian data dan kesimpulan. Adapun untuk menguji keabsahan data menggunakan triangulasi metode. Hasil penelitian ini menunjukan siswa introvert dan extrovert telah memenuhi semua tahapan berpikir visual menurut Bolton (looking, seeing, imagining, showing and telling). Adapun temuan yang menjadi simpulan penelitian ini adalah siswa introvert sangat berhati-hati sedangkan siswa extrovert cenderung kurang teliti dalam menyelesaikan masalah matematis.
\end{abstract}

Kata kunci: Berpikir visual matematis; extrovert; introvert; proses; tahapan Bolton.

\begin{abstract}
Visual thinking skill is important for students so it is needed more observation to see students visual thinking proces. This research aims to describe the visual thinking process based on Bolton stages that use extrovert or introvert personality types of students of SMA Negeri 1 Juwana to solving mathematical problems. In this research, the writer observed two extrovert students and two introvert students as research subjects. The data sources are taken from documentatiton, non-test/test and interviews. This research used data analysis reduction, presentation of data and conclusions. This research also used triangulation methods to test the validity of data. The result of this analysis showed that introvert and extrovert students have fulfilled all stages of visual thinking according to Bolton (looking, seeing, imagining, showing and telling). The conclusion of this research is the introverted students are very careful in making decisions while extrovert students tend to be less thorough in solving mathematical problems.
\end{abstract}

Keywords: Bolton; extrovert; introvert; mathematics visual thinking; process.

This is an open access article under the Creative Commons Attribution 4.0 International License

\section{PENDAHULUAN}

Berpikir merupakan kegiatan mental yang berlangsung saat seseorang mengalami kesulitan dalam menghadapi masalah dan membutuhkan solusi (Aini \& Hasanah, 2019). Berpikir merupakan metode agar menghasilkan representasi mental yang baru melalui suatu perubahan informasi dengan atribut mental, seperti: penilaian, pemecahan masalah dan imajinasi dengan interaksi yang lebih kompleks (Darmadi \& Handoyo, 2016). Oleh karena itu, berpikir merupakan representasi dari kegiatan mental seseorang saat menyelesaikan suatu permasalahan. 
DOI: https://doi.org/10.24127/ajpm.v10i2.3489

Permasalahan yang terjadi di Sekolah Menengah Atas ialah persentase Ujian Nasional Berbasis Komputer (UNBK) SMA Tahun Pelajaran 2018/2019 pada bahasan geometri yaitu $36,77 \%$. Hasil persentase tersebut dipengaruhi karena pemahaman siswa pada materi geometri yang masih rendah (Sumarni \& Prayitno, 2016). Menurut (Ariawan, 2017) menyatakan bahwa siswa mengalami kesulitan dalam pokok bahasan geometri sehingga diperlukan kemampuan berpikir visual untuk memvisualisasikan agar menjadi gambar, diagram, simbol dan angka sehingga mempermudah siswa dalam memecahkan masalah matematika.

Salah satu kemampuan siswa saat menyelesaikan masalah matematis yaitu kemampuan berpikir visual. Berpikir visual memiliki peran penting untuk memecahkan masalah matematika yang membutuhkan penalaran tingkat tinggi sehingga siswa tidak kesulitan ketika memahami konsep (Paradesa, 2017).

Tahapan proses berpikir visual menurut Bolton (2011) yaitu looking, seeing, imagining, showing and telling. Tahap melihat (looking) yakni siwa dapat mengumpulkan dan mengidentifikasi inti permasalahan. Tahap kedua mengenali (seeing) pada tahap ini peserta didik mampu untuk memilah-milah suatu permasalahan dan mengelompokkannya. Tahap ketiga membayangkan (imagining) yaitu siswa mampu menemukan solusi dari mengenali permasalahan tersebut. Tahap memperhatikan dan menceritakan (showing and telling) pada tahap ini siswa mampu menjelaskan kembali apa yang didapat pada tahap pertama lalu mengkomunikasikannya.

Siswa memiliki proses berpikir yang berbeda ketika memecahkan permasalahan matematis. Hal ini didukung dengan (Hamidah \& Suherman, 2016) bahwa tipe kepribadian mempengaruhi proses berpikir setiap siswa. Tipe kepribadian dibagi menjadi dua yaitu kepribadian extsrovert dan introvert. Tipe kepribadian extrovert cenderung senang bersosialisasi (Zafar et al, 2017) sedangkan tipe kepribadian introvert memiliki kepercayaan diri yang rendah sehingga sukar untuk bersosialisasi (Rahmat, 2014). Berdasarkan latar belakang yang diuraikan, penelitian ini hendak mendeskripsikan kemampuan berpikir visual matematis siswa extrovert dan introvert di SMA dengan tahapan Bolton.

\section{METODE PENELITIAN}

Jenis penelitian ini ialah penelitian kualitatif deskriptif. Subjek dalam penelitian ini yaitu 2 siswa introvert dan 2 siswa extrovert kelas XII IPS 2 di SMA Negeri 1 Juwana yang berkemampuan tinggi dalam Penilaian Tengah Semester (PTS) Ganjil Tahun Ajaran 2020/2021 pada mata pelajaran matematika. Subjek yang dipilih dari siswa yang memiliki kemampuan tinggi dalam Mata Pelajaran Matematika, sedangkan untuk memilih subyek berkepribadian extrovert dan introvert menggunakan kuisioner tipe kekpribadian melalui google form. Instrumen dalam penelitian ini yaitu kuisioner tipe kepribadian dan 2 soal HOTS materi dimensi tiga.

Bentuk soal berpikir visual pada materi dimensi tiga seperti: (1) Seekor semut merayap pada kubus ABCD.EFGH dengan rusuk 8 meter. ABCD sebagai bidang dasar. Semut tersebut merayap mulai dari titik $\mathrm{M}$ yang terletak 2 meter di atas $\mathrm{A}$ dan berhenti di titik $\mathrm{N}$ yang terletak 2 meter di bawah titik G. Hitunglah lintasan 
terpendek yang ditempuh semut tersebut!; (2) Tiga ekor semut merayap pada kubus ABCD.EFGH dengan rusuk 10 meter. Tiga ekor semut etrsebut berada pada bidang dasar kubus ABCD. Semut tersebut akan berlomba menuju titik sudut atap ruangan dengan ketentuan harus berkumpul pada salah satu titik bidang dasar. Hitunglah jarak minimum yang ditempuh semut tersebut.

Teknik pengumpulan data dalam penelitian ini dokumentasi saat subjek mengerjakan soal dimensi tiga, non-tes saat subjek mengisi kuisioner kepribadian melalui google classroom dan wawancara. Triangulasi yang digunakan ialah triangulasi metode. Analisis data pada penelitian ini adalah: (1) Reduksi data dilakukan dengan memberikan angket tipe kepribadian lalu memberikan soal berpikir visual dimensi tiga; (2) Penyajian data disajikan dalam bentuk flowchart; (3) Kesimpulan dari rangkaian penelitian.

\section{HASIL DAN PEMBAHASAN}

Penelitian ini dilaksanakan dari bulan September sampai November 2020 di SMA Negeri 1 Juwana. Sesuai dengan hasil Penilaian Tengah Semester (PTS) I dan kuisioner tipe kepribadian extrovert dan introvert pada 31 siswa kelas XII, diperoleh 4 subjek yang berkemampuan tinggi pada mata pelajaran Matematika dengan kriteria seperti pada Tabel 1 .

Tabel 1. Karakteristik subjek penelitian

\begin{tabular}{cccc}
\hline Inisial & Kategori & $\begin{array}{c}\text { Nilai } \\
\text { PTS }\end{array}$ & $\begin{array}{c}\text { Tipe } \\
\text { kepribadian }\end{array}$ \\
\hline BRK & Tinggi & 92 & Introvert \\
FAP & Tinggi & 91 & Introvert \\
RCCM & Tinggi & 90 & Extrovert \\
TBAW & Tinggi & 92 & Extrovert \\
\hline
\end{tabular}

\section{Proses Berpikir Visual Siswa Introvert} Berkemampuan Tinggi

Proses berpikir visual subjek BRK bepribadian introvert dapat dilihat pada Gambar 1.

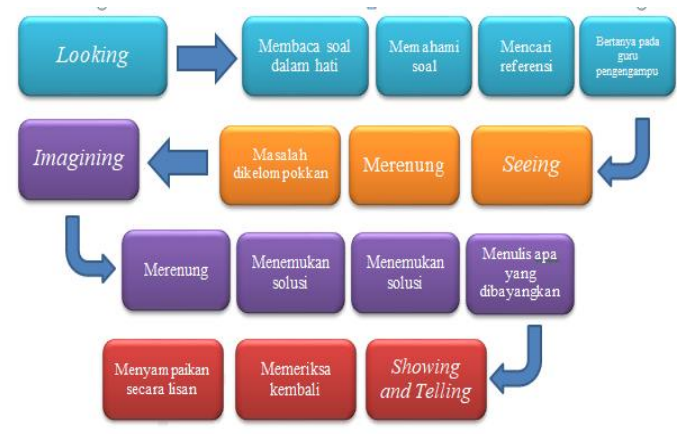

Gambar 1. Proses berpikir visual BRK subjek introvert

Pada tahap looking, subjek membaca soal dalam hati, subjek mampu mengidentifikasi soal dengan bantuan dari guru pengampu. Tahap seeing subjek BRK mengelompokan permasalahan yang terdapat pada soal. Tahap imagining subjek merenung agar menemukan solusi, subjek mulai menyelesaikan soal dengan menggambar kubus ABCDEFGH. Tahap showing and telling subjek memeriksa kembali dengan hati-hati dan menyampaikan secara lisan.

Proses berpikir visual subjek BRK berkepribadian introvert disajikan dalam bentuk flowchart seperti pada Gambar 2.

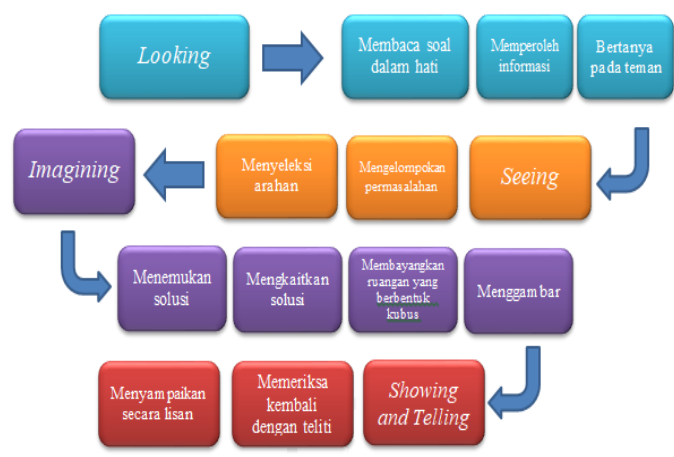

Gambar 2. Proses berpikir visual FAP subjek introvert 
DOI: https://doi.org/10.24127/ajpm.v10i2.3489

Tahap looking oleh subjek FAP, subjek membaca kedua soal dalam hati lalu mendapatkan informasi kemudian subjek lebih bertanya kepada teman dibanding dengan peneliti. Tahap seeing, subjek mengelompokkan informasi pada soal, subjek menyeleksi beberapa arahan dari guru pengampu agar menemukan solusi. Tahap imagining subjek membayangkan ruangan yang berbentuk kubus lalu menyelesaikan soal dengan rumus phytagoras sehingga subjek menemukan solusi dari permasalahan tersebut. Pada tahap showing and telling subjek FAP memeriksa kembali jawaban dengan bertanya kepada peneliti lalu subjek menjelaskan secara singkat melalui aplikasi google meet.

Subjek introvert FAP dan BRK telah memenuhi semua tahapan berpikir visual Bolton (2011). Hasil proses berpikir visual subjek introvert BRK dan FAP dapat dilihat pada Tabel 2.

Tabel 2. Hasil data subjek introvert

\begin{tabular}{ll}
$\begin{array}{c}\text { Tahapan Proses } \\
\text { Berpikir Visual }\end{array}$ & Indikator Proses Berpikir Visual Subjek Introvert \\
\hline Looking & - Siswa membaca soal dalam hati \\
& - Siswa mengindentifikasi \\
& - Siswa bertanya kepada guru pengampu dan teman sebaya \\
& sebagai orang yang telah lama dikenal. \\
Seeing & - siswa merenung agar menemukan solusi \\
& - siswa mengelompokan permasalahan \\
Imagining & - siswa membayangkan ruangan yang berbentuk kubus \\
& - siswa menemukan solusi \\
Showing and telling & - Siswa meneliti pekerjaan dengan hati-hati. \\
& - Siswa memastikan kembali dengan bertanya kepada \\
& peneliti. \\
&
\end{tabular}

Berdasarkan Tabel 2 yaitu hasil data subjek introvert dari subjek BRK dan FAP telah memenuhi Tahapan Bolton (2011). Pada tahap looking kedua subjek membaca soal dalam hati, mengidentifikasi soal materi geometri ruang dan bertanya kepada orang yang telah lama dikenal subjek. Pada tahap ini subjek introvert sukar bersosialisasi dengan orang yang baru ditemui. Tahap seeing, subjek introvert mengelompokan permasalahan dan mennemukan solusi dari permasalahan tersebut. Tahap imagining subjek introvert membayangkan bangun ruang kubus dan tahap terakhir subjek meneliti hasil pekerjaan dengan hatihati.

Proses Berpikir Visual Siswa Extrovert Berkemampuan Tinggi

Proses berpikir visual TBAW yang berkepribadian extrovert dapat dilihat pada Gambar 3. Pada tahap pertama looking, subjek mengidentifikasi masalah dengan membaca sambil bersuara, mencari referensi dan bertanya kepada peneliti dari pada teman sebaya. Tahap seeing subjek mengelompokkan dan menyeleksi masalah. Pada tahap ini subjek melakukan aktivitas fisik seperti berpindah tempat duduk agar lebih fokus dalam menyelesaikan masalah. 
Tahap imagining subjek menemukan solusi dengan membayangkan semut yang terletak di dalam kubus ABCD.EFGH. Tahap showing and

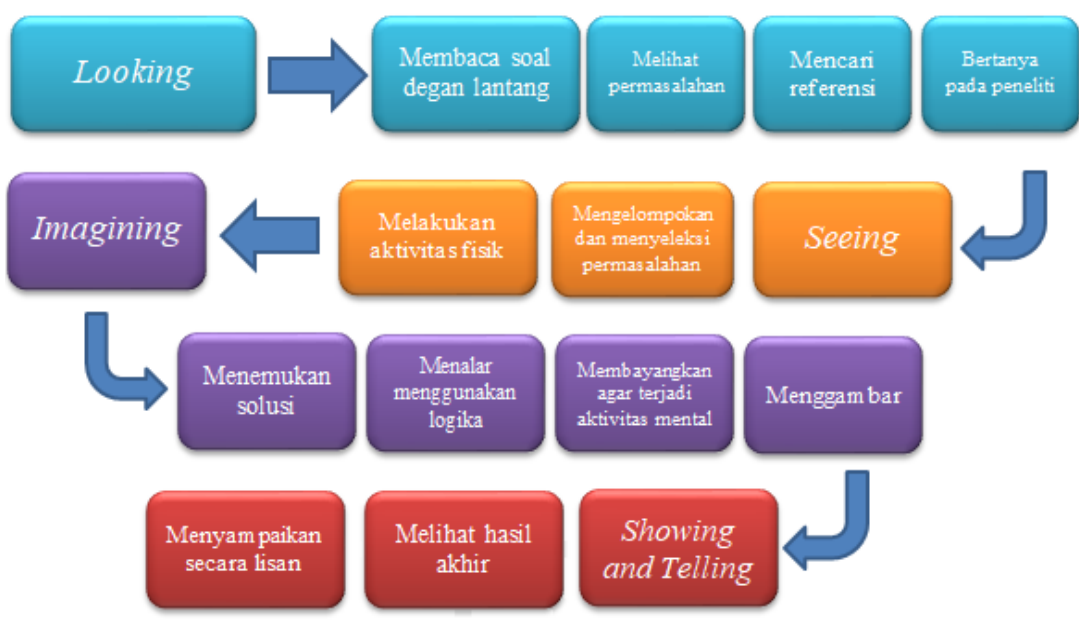

Gambar 3. Proses berpikir visual TBAW subjek extrovert

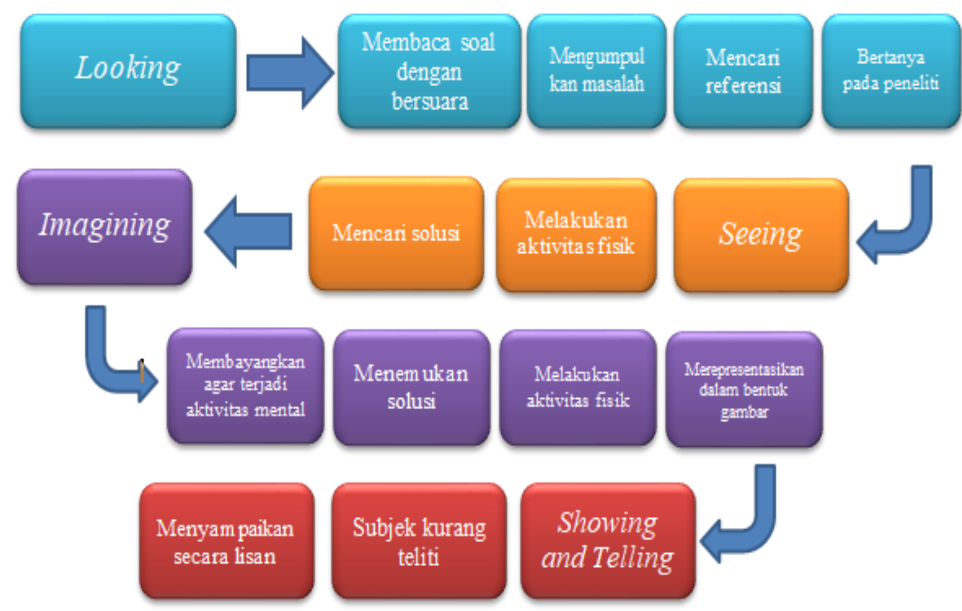

Gambar 4. Proses berpikir visual RCCM subjek extrovert

Selanjutnya, proses berpikir visual RCCM yang berkepribadian extrovert dapat dilihat pada Gambar 4. Pada tahap looking, subjek membaca soal dengan bersuara, subjek mengumpulkan masalah dengan mencari referensi dan lebih bertanya kepada peneliti daripada guru pengampu. Tahap seeing subjek RCCM mencari solusi dari permasalahan tersebut. Tahap imagining subjek membayangkan ruangan yang berbentuk kubus, subjek menemukan telling subjek TBAW tidak memeriksa hasil jawaban dengan teliti kemudian menjelaskan secara lisan kepada peneliti melalui aplikasi google meet. 
DOI: https://doi.org/10.24127/ajpm.v10i2.3489

Tabel 3. Hasil data subjek extrovert dari TBAW dan RCCM

\begin{tabular}{ll}
\hline $\begin{array}{c}\text { Tahapan Proses } \\
\text { Berpikir Visual }\end{array}$ & \multicolumn{1}{c}{$\begin{array}{c}\text { Indikator Proses Berpikir Visual } \\
\text { Subjek Extrovert }\end{array}$} \\
\hline Looking & - Siswa membaca soal dengan bersuara \\
& - Siswa mengindentifikasi \\
& - Siswa mengumpulkan permasalahan dengan mencari \\
& - referensi pada buku \\
- Siswa bertanya kepada peneliti \\
- Siswa membaca soal \\
- Siswa melakukan aktivitas fisik \\
Imagining & - Siswa mengelompokan permasalahan \\
& - Siswa membayangkan ruangan yang berbentuk kubus \\
Showing and telling & - Siswa menemukan solusi \\
& - Siswa menetapkan langkah penyelesaian \\
& - Siswa menjelaskan kembali secara lisan
\end{tabular}

Hasil data subjek extrovert TBAW dan RCCM pada tahap looking yaitu subjek membaca soal dengan bersuara karena subjek extrovert lebih percaya diri untuk bersuara. Tahap seeing subjek melakuka aktivitas fisik seperti mencari sumber referensi lain agar subjek dapat menemukan solusi. Tahap imagining subjek membayangkan ruangan yang berbentuk kubus agar menemukan solusi dan menetapkan langkah penyelesaian. Tahap showing and telling subjek tidak meneliti dengan hati-hati karena subjek sangat percaya diri.

Berdasarkan deskripsi hasil penelitian sudah sesuai dengan penelitian (Aini \& Hasanah, 2019); (Darmadi \& Handoyo, 2016); (Surya, 2013) bahwa semua subjek introvert dan extrovert telah memenuhi tahapan berpikir visual menurut Bolton yaitu tahap looking, seeing, imagining, showing and telling.

Proses berpikir visual siswa dalam memecahkan masalah matematis dengan tipe kepribadian extrovert dan introvert yaitu sebagai berikut:

A) Siswa Introvert
Tahap looking, siswa membaca soal dalam hati, siswa mengidentifikasi soal dan bertanya kepada guru pengampu atau teman sebaya sebagai orang yang telah lama dikenal. Tahap seeing siswa merenung agar menemukan solusi lalu siswa mengelompokkan permasalahan. Tahap imagining siswa membayangkan ruangan yang berbentuk kubus lalu siswa menyelesaikan permasalahan tersebut. Pada tahap ini, siswa tidak melakukan aktivitas fisik. Tahap showing and telling siswa meneliti hasil pekerjaan dengan hati-hati, siswa bertanya kepada peneliti lalu siswa menjelaskan secara singkat melalui aplikasi google meet. Hal ini sejalan dengan penelitian (Arini, 2016) dan (Siskawati, 2015) yang menyatakan bahwa siswa introvert cenderung berhati-hati dalam mengambil keputusan sehingga siswa meneliti kembali langkah-langkah dalam menyelesaikan masalah matematis.

\section{B) Siswa Extrovert}

Tahap looking, siswa membaca soal dengan bersuara, siswa mampu mengidentifikasi dan mengumpulkan 
permasalahan agar memudahkan siswa dalam mengerjakan soal, siswa juga bertanya kepada peneliti dari pada bertanya pada teman sebaya. Tahap seeing siswa membaca soal berkali-kali, siswa extrovert melakukan aktivitas fisik dan berhasil untuk mengelompokkan permasalahan. Tahap imagining siswa membayangkan ruangan yang berbentuk kubus, menemukan solusi dengan cara menalar dan menetapkan langkah penyelesaian. Tahap showing and imagining siswa extrovert sangat percaya diri sehingga tidak memeriksa kembali hasil pekerjaan dan menjelaskan secara lisan. Hal ini sejalan dengan (Arini, 2016) menyatakan bahwa subjek extrovert kurang teliti dalam pengambilan keputusan sehingga perhitungan subjek extrovert kurang tepat.

Beberapa temuan dalam penelitian ini yaitu siswa introvert cenderung sukar bersosialisasi dengan peneliti sebagai orang baru sehingga lebih memilih bertanya kepada teman sebaya untuk berdiskusi akan tetapi subjek introvert lebih teliti saat mengerjakan soal. Subjek extrovert lebih mudah bersosialisasi dengan orang baru sehingga berani untuk bertanya kepada peneliti ketika mengerjakan soal. Kelebihan dari penelitian ini ialah setiap siswa tidak hanya memiliki proses berpikir kreatif dan kritis saja tetapi siswa juga memiliki kemampuan berpikir visual yang berguna untuk memvisualisasikan pikiran mereka menjadi sebuah symbol atau diagram. Kekurangan dalam penelitian ini adalah kurangnya rekomendasi subjek karena berpikir visual lebih direkomendasikan untuk subjek yang tunanetra agar peneliti yang akan datang tahu bagaimana cara subjek tunanetra mengimplementasikan bayangan mereka menjadi sebuah gambar atau symbol.

Perbedaan penelitian sekarang dengan penelitian terdahulu ialah sebagai berikut: (1) (Darmadi \& Handoyo, 2016) meneliti proses berpikir visual dengan tahapan polya; (2) (Siskawati, 2015) meneliti profil berpikir siswa introvert; (3) (Pangestu \& Hasti Yunianta, 2019) meneliti tentang proses siswa extrovert dan introvert; (4) (Sriyanto, 2019) meneliti strategi berpikir visual bagi peserta didik gangguan kecemasan sosial untuk mengembangkan keterampilan; (Milla \& Patricia,2018) menganalisis kesulitan kemampuan berpikir visual ketika memahami materi himpunan. Hasil dalam penelitian ini ialah siswa extrovert dan introvert telah memenuhi semua tahapan Bolton seperti looking, seeing, imagining, showing and telling.

\section{KESIMPULAN DAN SARAN}

Berdasarkan hasil dan pembahasan, dapat ditarik kesimpulan: (1) subjek introvert dan extrovert telah memenuhi semua tahapan Bolton seperti looking, seeing, imagining, showing and telling; (2) saat mengerjakan soal dimensi tiga, subjek introvert sungkan untuk bertanya kepada peneliti sedangkan subjek extrovert mudah beradaptasi dengan lingkungan yang baru dengan bertanya kepada peneliti; (3) subjek introvert sangat berhati-hati dalam mengambil keputusan sehingga meneliti jawaban berkali-kali untuk memastikan benar sedangkan subjek extrovert sangat percaya diri dan kurang teliti saat mengerjakan soal sehingga tidak semua jawaban bernilai benar.

Saran yang diberikan dalam penelitian agar meningkatkan kemampuan berpikir visual siswa ialah pendidik harus memotivasi siswa untuk 
lebih semangat belajar dan sering memberikan latihan soal pada pokok bahasan geometri atau dimensi tiga sehingga melatih siswa untuk memvisualisasikan pikiran mereka agar siswa mudah dalam memecahan masalah matematis sedangkan saran untuk penelitian yang akan datang ialah dapat menjadi acuan untuk meneliti proses berpikir visual siswa pada mata pelajaran matematika yang memiliki persentase UNBK paling rendah.

\section{DAFTAR PUSTAKA.}

Aini, S. D., \& Hasanah, S. I. (2019). Berpikir Visual dan Memecahkan Masalah: Apakah Berbeda Berdasarkan Gender? JNPM (Jurnal Nasional Pendidikan Matematika), 3(2), 177. https://doi.org/10.33603/jnpm.v3i2 .2192

Ariawan, R. (2017). Pengaruh Pembelajaran Visual Thinking Disertai Aktivitas Quick on the Draw Terhadap Kemampuan Pemecahan Masalah Dan Komunikasi Matematis. Jurnal Penelitian dan Pembelajaran Matematika, $10(1)$. https://doi.org/10.30870/jppm.v10i 1.1193

Arini, Z. (2016). Profil Kemampuan Penalaran Siswa Smp Dalam Menyelesaikan Masalah Matematika Ditinjau Dari Tipe Kepribadian Extrovert Dan Introvert. MATHEdunesa, 5(2).

Bolton, S. (2011). Decoding Visual Thinking. Naver Workshop, Visualising Creative Strategies.

Darmadi \& Handoyo, B. (2016). Profil Berpikir Visual Mahasiswa Calon Guru Matematika Dengan Gaya Belajar Visual dalam Menyelesaikan Masalah Triginometri. Jurnal Matematika
Kreatif-Inovatif, 02(01), 75-84.

Hamidah, K., \& Suherman, S. (2016). Proses Berpikir Matematis Siswa dalam Menyelesaikan Masalah Matematika di tinjau dari Tipe Kepribadian Keirsey. Al-Jabar: Jurnal Pendidikan Matematika, 7(2), 231-248. https://doi.org/10.24042/ajpm.v7i2. 38

Milla, M. L., \& Patricia, F. A. (2018). Analisis Kesulitan Berpikir Visual dalam Memahami Konsep pada Materi Himpunan. PRISMATIKA (Jurnal Pendidikan dan Riset Matematika), 1(1), 64-68. https://doi.org/10.33503/prismatika .v1i1.305

Pangestu, N. S., \& Hasti Yunianta, T. N. (2019). Proses Berpikir Kreatif Matematis Siswa Extrovert dan Introvert SMP Kelas VIII Berdasarkan Tahapan Wallas. Mosharafa: Jurnal Pendidikan Matematika, 8(2), 215-226. https://doi.org/10.31980/mosharafa .v8i2.472

Paradesa, R. (2017). Pengembangan Bahan Ajar Geometri Transformasi Berbasis Visual. Jurnal Pendidikan Matematika RAFA, 2(1), 56-84.

Rahmat, W. (2014). Pengaruh tipe kepribadian dan kualitas persahabatan dengan kepercayaan pada remaja akhir. PSIKOBORNEO (Jurnal Ilmiah Psikologi), S2(2), 206-216.

Siskawati, F. S. (2015). Profil Penalaran Siswa SMP Dengan Kepribadian Introvert Dalam Memecahkan Masalah Matematika. Educazione:Jurnal Pendidikan, Pembelajaran dan Bimbingan dan Konseling, 3(2), 177-194.

Sriyanto, S., Febrianta, Y., \& Yuwono, P. H. (2019). Strategi Berpikir Visual bagi Peserta Didik 
DOI: https://doi.org/10.24127/ajpm.v10i2.3489

Gangguan Kecemasan Sosial untuk Mengembangkan Keterampilan Sosial. JSSH (Jurnal Sains Sosial Dan Humaniora), 3(1), 65. https://doi.org/10.30595/jssh.v3i1. 3064

Sumarni, S., \& Prayitno, A. T. (2016). Kemampuan Visual-Spatial Thinking Dalam Geometri Ruang Mahasiswa Universitas Kuningan. JES-MAT (Jurnal Edukasi Dan Sains Matematika), 2(2). https://doi.org/10.25134/jesmat.v2i2.349

Surya, E., Sabandar, J., Kusumah, Y. S., \& Darhim. (2013). Improving of junior high school visual thinking representation ability in mathematical problem solving by CTL. Journal on Mathematics Education, 4(1), 113-126. https://doi.org/10.22342/jme.4.1.56 8.113-126

Zafar, S., Khan, Z. A., \& Meenakshi, K. (2017). Extraversion-introversion tendencies and their relationship with ESL proficiency: A study of Chinese students in Vellore, India. Pertanika Journal of Social Sciences and Humanities, 25(2), 687-703. 